\title{
P-Body Components, microRNA Regulation, and Synaptic Plasticity
}

\author{
Jens Hillebrand ${ }^{1}$, Scott A. Barbee ${ }^{2,3,4, *}$, and Mani Ramaswami ${ }^{1,2,3, *}$ \\ ${ }^{1}$ Smurfit Institute of Genetics and TCIN, Lloyd Building, Trinity College Dublin, \\ Dublin-2, Ireland; ${ }^{2}$ Department of Molecular and Cellular Biology, ${ }^{3} A R L$ Division of \\ Neurobiology, University of Arizona, Tucson, AZ 85721; ${ }^{4}$ Present address: \\ Department of Biological Sciences, University of Denver, Denver, CO 80208 \\ E-mail: jens.hillebrand@tcd.ie; barbeesa@u.arizona.edu; mani@u.arizona.edu
}

Received June 22, 2007; Revised July 12, 2007; Accepted July 13, 2007; Published November 2, 2007

What is the protein apparatus required for microRNA (miRNA) function and translational repression in neurons? This article reviews our recent work on Me31B, a conserved $\mathrm{P}$ body protein present on Staufen-containing neuronal and maternal ribonucleoprotein (RNP) particles, which is required for dendrite morphogenesis and miRNA function in vivo. In addition, it provides new data to show that Me31B is present on and regulates formation of P-bodies in the Drosophila wing disc, where it has a general role in the regulation of miRNA function. While illuminating the function of this important RNA regulatory molecule, it also brings into focus a hypothesis of potentially broad significance. Namely, that P-body proteins may play important roles in regulation of dendrite-localized mRNAs and, thereby, in synaptic plasticity. A wide range of protein localization and early functional data support this hypothesis. We also discuss current knowledge of RNP particles that mediate translational repression and the implications of these findings for understanding translational control in neurons.

KEYWORDS: P-body, microRNA, synaptic plasticity, neuronal granules, translational control, Me31B, FMRP, Drosophila

\section{INTRODUCTION}

A significant body of work argues strongly for the role of new protein synthesis in the establishment of long-term memory (LTM). For example, studies of long-term potentiation (LTP) and long-term depression (LTD) in mammals have identified two distinct phases of plasticity: an early phase (typically lasting 1-3 h) that is independent of new protein synthesis and a late phase (lasting $>8 \mathrm{~h}$ ) that is dependent on new protein synthesis[1]. Many recent investigations of molecular mechanisms underlying new protein synthesis have focused on local regulation of mRNA translation. In neurons, local mRNA translation serves many important functions during development or growth of axons and dendrites, and the regulation of synaptic plasticity. Local mRNA translation is regulated by sequence motifs within mRNAs in combination with specific RNA binding proteins and noncoding RNAs (ncRNAs). Together, the composition of these ribonucleoprotein (RNP) complexes determines whether mRNAs are transported to a specific location (e.g., to the synapse), locally translated, or targeted for storage and/or degradation. 
Many excellent reviews have been written covering the topics of mRNA transport[2,3,4], local translation[1,5,6], RNP granule structure and function[7,8,9], and ncRNA function[10,11]) in neurons. Readers are directed to these articles for more detailed discussion of each of these topics.

Here we focus on recent evidence suggesting that neuronal RNPs, particularly in Drosophila neurons, are similar in structure and function to cytoplasmic RNA processing bodies (also called GW- or DCPbodies, but hereafter referred to as P-bodies) - conserved RNPs present in all cells from yeast to mammals[12]. P-bodies, initially identified as cytoplasmic sites for mRNA turnover to which RNA decapping and degradative enzymes are localized, have since been shown to also act as sites for transient storage of translationally repressed mRNAs[13]. Additionally, recent evidence suggests that there is a link between P-bodies and the function of small interfering RNAs (siRNAs) and microRNAs (miRNAs) $[8,14,15,16]$.

Translational regulatory proteins that provide local control of mRNA translation in neurons are beginning to be identified. These proteins include not only classical translational repressor/activator proteins, but also molecules proposed to function in the miRNA pathway (such as the Fragile X Mental Retardation Protein, FMRP). Given the demonstrated association of several P-body proteins with FMRPand FMRP/Staufen-containing RNPs, it is of obvious interest to ask whether P-body proteins are involved in the function of neuronal miRNAs. It has recently been shown that specific miRNAs and components of the miRNA pathway regulate important aspects of neuronal development and plasticity[17,18]. Below, we discuss in greater detail the implications of P-body structure and function on miRNA-mediated regulation of neuronal development, synaptic plasticity, and long-term memory. Specifically, do P-bodies and/or P-body proteins play a role in the mechanism underlying local protein synthesis at specific synapses?

\section{NEURONS CONTAIN A DIVERSE POPULATION OF RNPS WITH CONSERVED STRUCTURE AND FUNCTION}

Regulation of local mRNA translation in neurons is mediated both during transport along neuronal processes and at synaptic sites. During transport, translational repression occurs in large RNPs broadly termed "neuronal granules" or "transport granules" (which we hereafter refer to as NGs). At least two excellent reviews recently categorized macroscopic (visible by light microscopy) NGs into a number of distinct RNP "subclasses" based on homology to non-neuronal cytoplasmic RNPs[7,9]. These granule "subclasses" include P-bodies, stress granules, the RNA-induced silencing complex (RISC), RNA granules, and transport particles[9]. Each is characterized by the presence (or absence) of specific protein components. This classification scheme is supported, in part, by the observation that Drosophila neurons do not appear to contain a homogenous population of RNPs[12].

However, at least two lines of evidence suggest that most NGs are, in fact, structurally and functionally related. First, NGs in cultured Drosophila neurons contain conserved components of mammalian NGs and other cytoplasmic RNPs (Table 1). For example, most NGs can be broadly identified by the presence of three highly conserved proteins: the dsRNA-binding protein, Staufen[19,20,21]; the extensively studied FMRP[12,22,23]; and the DEAD-box RNA helicase, $\mathrm{RCK} / \mathrm{Me} 31 \mathrm{~B} / \mathrm{Dhh} 1 \mathrm{p}[24,25,26]$. Second, all NGs are sites for the storage of translationally repressed mRNAs[27,28,29,30]. The existence of biochemically diverse particles is at least partially accounted for by observations indicating a rapid exchange of proteins between these particles, or during the maturation of particles as they grow in size. For example, fluorescence recovery after photobleaching (FRAP) analysis reveals that many specific RNP-associated proteins rapidly shuttle in and out of NGs as well as RNPs in non-neuronal cells[12,31,32,33,34]. At present, data are most consistent with a model in which RNPs are highly dynamic, and suggest that NGs are cellular compartments where mRNAs are remodeled and sorted for mRNA decay, translational repression, and/or mRNA storage (Fig. 1). Taken together with our recent finding that at least ten P-body proteins are present on Staufen- and FMRP-containing NGs in Drosophila neurons[12], these data suggest that NGs share a fundamentally conserved structure and function with cytoplasmic P-bodies. 
TABLE 1

Conserved Components of P-Bodies and NGs

\begin{tabular}{|c|c|c|c|}
\hline Protein Class & $\begin{array}{l}\text { Mammalian, Fly, } \\
\text { and Yeast P-Bodies }\end{array}$ & $\begin{array}{l}\text { Drosophila } \\
\text { NGs }^{b}\end{array}$ & Mammalian NGs ${ }^{c}$ \\
\hline \multicolumn{4}{|l|}{ Conserved NG components } \\
\hline Fragile $X$-like & FMRP & dFMR1 & FMRP, FXR1, FXR2 \\
\hline RNA transport & Stau & Stau, Btz & Stau, Btz \\
\hline DEAD-box RNA helicase & RCK/Me31B/Dhh1p & Me31B & $?$ \\
\hline \multicolumn{4}{|l|}{ Core P-body components } \\
\hline 5' to 3' RNA exoribonuclease & Xrn1p & Pcm & ? \\
\hline $\begin{array}{l}\text { Sm-like and FDF domain; involved } \\
\text { in repression }\end{array}$ & RAP55/Tral/Scd6pi & Tral & $?$ \\
\hline Enhancers of decapping & Edc3p, Pat1 $p^{h}$ & $?$ & ? \\
\hline Sm-like involved in decapping & Lsm1-7p & $?$ & $?$ \\
\hline Decapping enzymes & Dcp1p/Dcp2p & $\begin{array}{l}\text { DCP1 (DCP2 not } \\
\quad \text { examined) }\end{array}$ & \\
\hline \multicolumn{4}{|l|}{ miRNA/siRNA (RISC) components } \\
\hline miRNA, siRNA machinery & mAGO1, mAGO2 & Ago-2 & ? \\
\hline \multicolumn{4}{|l|}{ NMD components } \\
\hline Helicase required for $\mathrm{NMD}^{\mathrm{g}}$ & Upf-1 & Upf-1 & $?$ \\
\hline \multicolumn{4}{|c|}{ RNA-binding proteins and translational repressors } \\
\hline Cap-binding & elF4E $E^{d, j}$ & elF4E ${ }^{\text {also } f^{*}}$ & Under some conditions \\
\hline elF4E-binding & elF4E- $\mathrm{T}^{\mathrm{j}}$ & Cup & $?$ \\
\hline Poly(A)-binding & PABP $^{d}$ & $\mathrm{PABP}^{\mathrm{f*}}$ & $?$ \\
\hline Zip-code binding & $?$ & Imp & ZBP1 \\
\hline Puf domain & ? & Pum & $?$ \\
\hline $\mathrm{CCHC}$ Zn-finger domain & $?$ & Nanos $^{\text {also } \mathrm{e}^{\star}}$ & ? \\
\hline Y-box & ? & Yps & ? \\
\hline
\end{tabular}

? Ortholog present, but association with RNA granules has not been described.

a $\quad[19,23,25,31,37,76]$

b $[12]($ except PABP)

c $[20,24,32,77]$

d elF4E and PABP can associate with P-bodies in yeast under conditions of translational arrest induced by glucose deprivation[78].

e $[79]^{*}$

f $[80]^{*}$ (*Refs. e and f describe particles likely to be, but not clearly established as, neuronal RNA granules.)

g UPF1 has also been shown to interact with Stau in a Stau-mediated NMD pathway[81].

h Pat1p acts as a general repressor of translation in yeast[40].

I $[12,82]$

j [31] 


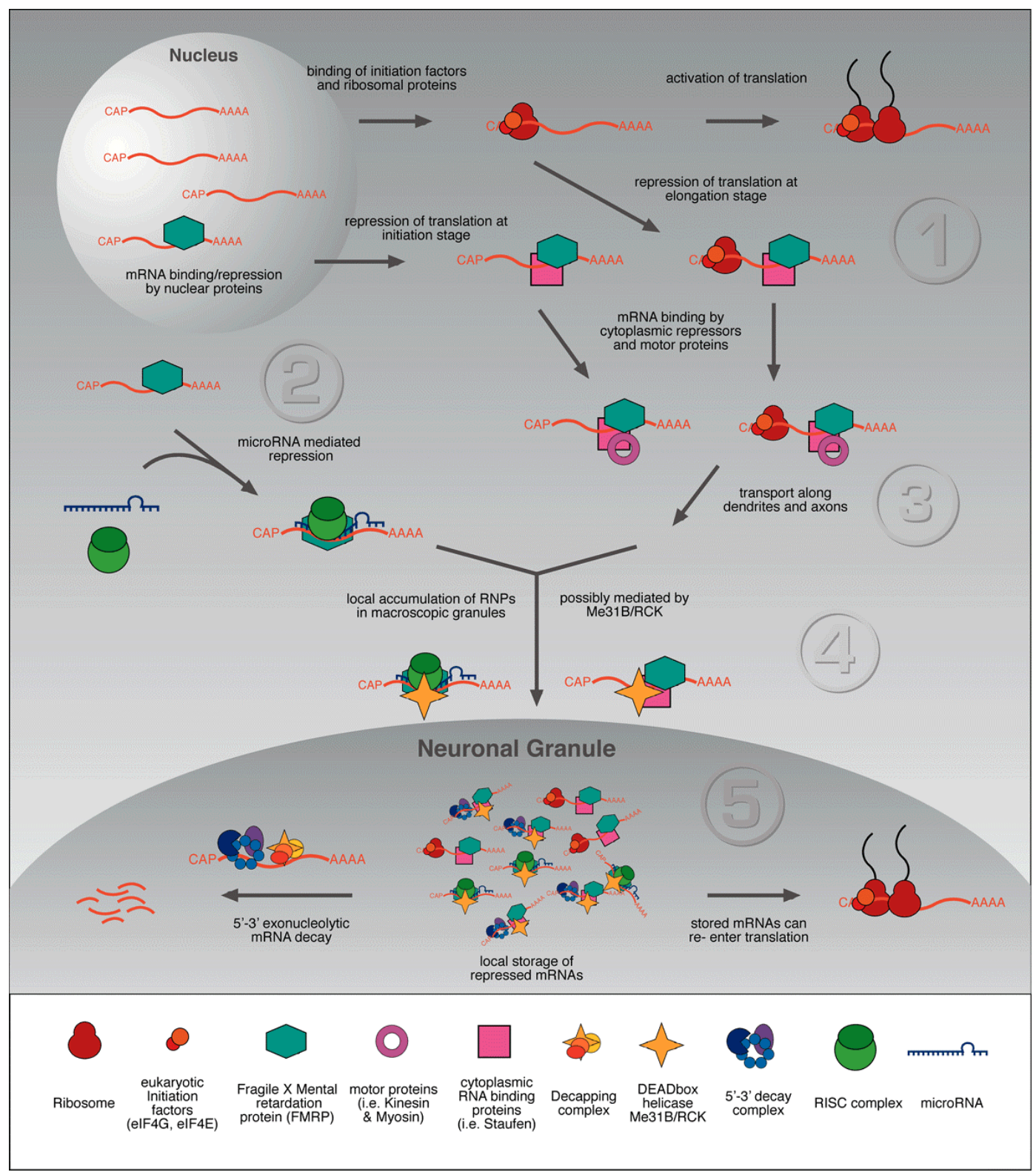

FIGURE 1. Model. Local protein synthesis in neurons plays a major role in neuronal development and synaptic plasticity. In order to regulate local translation, a neuron uses different mechanisms to repress, transport, store, degrade, and derepress mRNAs. This model gives an overview of different mRNP particles and their interaction. (1) Translation is initiated by the binding of eukaryotic initiation factors (eIFs) and ribosomal proteins to the mRNA. At this stage, specific mRNA binding proteins can repress translation at the elongation stage. Alternatively, mRNAs can be repressed before ribosomal proteins bind to the mRNA, blocking translation at the initiation stage. mRNPs containing mRNAs blocked at those two stages can be distinguished by the presence or absence of ribosomes. (2) The miRNA pathway represents an alternative way to repress mRNA translation. miRNAs are noncoding small RNAs (on average $22 \mathrm{nt}$ long) derived from double-stranded premiRNAs. When attached to the RISC, miRNAs bind to specific sequences in the UTR of their target mRNAs and repress translation. As many miRNAs are expressed in the nervous system and a role for miRNAs in synaptic plasticity and memory formation has been shown, a major role for miRNA-mediated translational repression in neurons is implicated. (3) Translationally repressed mRNAs are bound by specific RNA binding proteins, translational repressors, and motor proteins, and form diverse mRNPs, which are transported along dendrites and axons. (4) Locally, i.e., at synapses or dendritic branch points, diverse mRNPs accumulate in macroscopic NGs. A main component of NGs is the DEAD-box helicase Me31B/Rck, which is required for the formation of somatic P-bodies; thus implicating a role for Me31B/RCK in the formation of macroscopic NGs. (5) NGs are highly dynamic structures. FRAP experiments in neurons showed that proteins and mRNAs can enter and exit mRNP particles very rapidly. Furthermore, recent data suggest that NGs are cellular compartments where mRNAs are remodeled and sorted. mRNAs can either be repressed and stored locally, enter the decay pathway (proteins involved in 5'-3' exonucleolytic decay are present in NGs), or mRNAs can exit NGs and reenter translation, resulting in local protein synthesis. 
The observation that NGs and P-bodies are structurally and functionally related is potentially important for two reasons. First, it would allow for the identification of a large number of wellcharacterized P-body proteins as regulators of neuronal translational control. Second, it poses the interesting possibility that local dendritic pools of mRNA may be regulated by an additional mechanism local mRNA turnover. Together, this raises an important question that needs to be addressed. What neuronal processes and mechanisms are regulated by P-bodies?

\section{P-BODY COMPONENTS ARE REGULATORS OF MRNA DECAY AND GENERAL TRANSLATIONAL REPRESSION}

P-bodies are large, macroscopic, cytoplasmic aggregates of translationally repressed mRNAs associated with the translational repression and decay machinery $[8,14]$. P-bodies were initially thought to be primarily sites of mRNA decapping and 5' to 3' exonucleolytic degradation[25]. Core P-body protein components are conserved from yeast to mammals (Table 1) and include: (a) the mRNA decay machinery, including the decapping enzymes Dcp1p/Dcp2p and the 5' to 3' exoribonuclease, Xrn1/Pcm; (b) the activators of decapping, Edc3p, RAP55/Scd6p, and the Lsm1p-7p complex; and (c) the enhancers of decapping and general translational repressors, Me31B/RCK/Dhh1p and Pat1p[8]. P-bodies also contain components of the RISC, including the Argonaute proteins (Ago1 and Ago2), indicating a role in miRNA/siRNA-mediated gene silencing[35,36,37,38].

P-bodies are now thought to also be sites of translational regulation via miRNA, nonsense-mediated decay (NMD), and general repression pathways[8]. Several lines of evidence suggest that P-body proteins also have direct functions in general translational repression in higher eukaryotes. First, the Xenopus ortholog of yeast Scd6p (RAP55) represses translation of reporter mRNAs in cell extract[39]. Second, the decapping coactivators, Patlp and Dhhlp, are general repressors of general translation in yeast[40]. Finally, orthologs of Dhh1p (Xp54, CGH-1, and Me31B) function in the translational repression of specific maternal mRNAs in Xenopus, C. elegans, and Drosophila, respectively[41,42,43,44].

The analysis of P-bodies in yeast and mammalian cells is identifying critical protein interactions with P-bodies and specific protein functional domains that mediate interactions essential for P-body formation, translational repression, and mRNA decay. These analyses will provide a wealth of tools to test the importance of specific proteins, protein assemblies, protein interactions, and cell biological processes in neuronal development, function, and plasticity.

\section{MIRNAS AND SYNAPTIC PLASTICITY}

Computational analysis of the human genome suggests that nearly one-third of human genes are regulated by $\sim 500$ miRNAs, a discovery of profound significance for gene regulation in multicellular organisms[45]. Of these miRNAs, a large number are expressed in the mammalian nervous system[30,46,47], and have been shown to regulate neuronal mRNAs directly[30,48,49].

Three important observations indicate a role for the miRNA pathway in synaptic plasticity and LTM formation. First, it has recently been shown that in the rat hippocampus, the brain-specific miRNA, miR134, controls dendritic spine morphogenesis via regulation of a mRNA encoding LimK1, a protein kinase that has been implicated in spine development[18]. In mammals, dendritic spine morphogenesis is thought to correlate strongly with synaptic plasticity[50,51,52]. Second, the FMRP protein has been shown to be required for dendritic spine morphogenesis in humans and synaptic plasticity in Drosophila[53,54,55]. Defects in FMRP results in Fragile X Syndrome, the most common form of inherited mental retardation in humans[6]. FMRP has been shown to interact with components of the miRNA pathway and, in some cases, is thought to be part of the RISC complex[56,57,58]. Finally, recent results in Drosophila directly connect the RISC machinery with synaptic plasticity and LTM formation. In the olfactory system, Ashraf et al.[17] showed that the RISC component Armitage is required for 
formation of LTM. Moreover, Armitage and Dicer-2 are involved in the regulation of synaptic translation of $\propto$-calcium/calmodulin-dependent protein kinase II ( $\propto$-CaMKII), a predicted target of the miRNAs miR-280 and miR-289. The neuronal RNA binding proteins Staufen and Kinesin Heavy Chain are also predicted miR-280 targets, whose neuronal expression is similarly enhanced in Dicer-2 and armitage mutants. Interestingly, LTM formation correlated strongly with increased $\propto$-CaMKII synthesis via an Armitage- or miRNA-dependant mechanism. These and other related studies of miRNAs in neurons have been recently reviewed[10,59,60].

\section{P-BODY COMPONENTS REGULATE MIRNA FUNCTION}

The first indication of a link between P-bodies and the miRNA/siRNA machinery was the discovery that the mammalian Argonaute proteins, components of the RISC complex, colocalized to cytoplasmic foci with the P-body proteins Dcp1/Dcp2[37,38,61]. Six additional lines of evidence indicate a relationship between miRNA function and P-bodies. First, depletion of GW182 (a mammalian P-body component hence the name GW bodies) in human or Drosophila cells impairs silencing by miRNAs (and to a lesser extent) siRNAs[35,37,62,63,64]. Second, AIN-1, a C. elegans protein similar to GW182, was shown to interact with components of the RISC complex and is required to target the Argonaute protein to cytoplasmic P-bodies[36]. Third, human and Drosophila cells depleted of the Dcp1/Dcp2 complex have impaired miRNA function[35,37,65]. Fourth, Me31B and RCK (the mammalian ortholog of Dhh1p) have been shown to regulate miRNA function in both Drosophila and mammalian cells[12,62]. Fifth, miR16 is required for AU-rich element (ARE)-mediated mRNA degradation, a process that requires an ARE binding protein (tristertraprolin or TTP) shown to localize to mammalian P-bodies[34,66]. Finally, reporter mRNAs targeted for translational repression by miRNAs become targeted to mammalian Pbodies in a miRNA-dependant manner[67]. Two recent studies have shown that the formation of macroscopic Drosophila and mammalian P-bodies are not required for miRNA-mediated gene regulation per se[19,68]. This leads to a model in which, although P-body components play essential roles in miRNA function, aggregation of proteins into large P-bodies is a consequence of, rather than a requirement for, miRNA activity.

\section{DROSOPHILA ME31B IS REQUIRED FOR P-BODY FORMATION AND MIRNA FUNCTION}

Our recent published work shows that Me31B, a member of the RCK/Dhh1p family of DEAD-box RNA helicases, localizes to NGs in cultured Drosophila neurons[12]. In yeast and Drosophila S2 cells, it is required for the formation of P-bodies[19,25]. Observations in cultured cells and subsequent in vivo studies implicate Me31B in general and miRNA/siRNA-mediated pathways for mRNA silencing[12,40,62]. Consistent with a role for Me31B in repression of dendritic branching, a process likely to be regulated by local translational control mechanisms, Me31B as well as two physically associated proteins, FMRP and Trailerhitch (Tral, the Drosophila ortholog of RAP55/Scd6p), have been shown to be required for dendrite morphogenesis in Drosophila sensory neurons[12].

Here we present some important additional data that support a role for Me31B in P-body formation and miRNA function in vivo. Consistent with earlier observations in Drosophila S2 cells[19], Fig. 2 shows that Me31B localizes to endogenous P-bodies in Drosophila wing imaginal disc cells. In accordance with previous observations in yeast[25], Me31B/RCK/Dhh1p is required for macroscopic Pbody formation in wing discs. Thus, depletion of Me31B either in me31b mutant cell clones created by mitotic recombination using the FRT/FLP system, or by RNA interference (RNAi), results in the loss of macroscopic P-bodies visualized by staining for independent P-body marker proteins. Me31B-deficient cells show greatly reduced number of bright foci that contain the core P-body components, Dcp1 (Fig. 2A-C) and Pcm (Fig. 2D-F). 

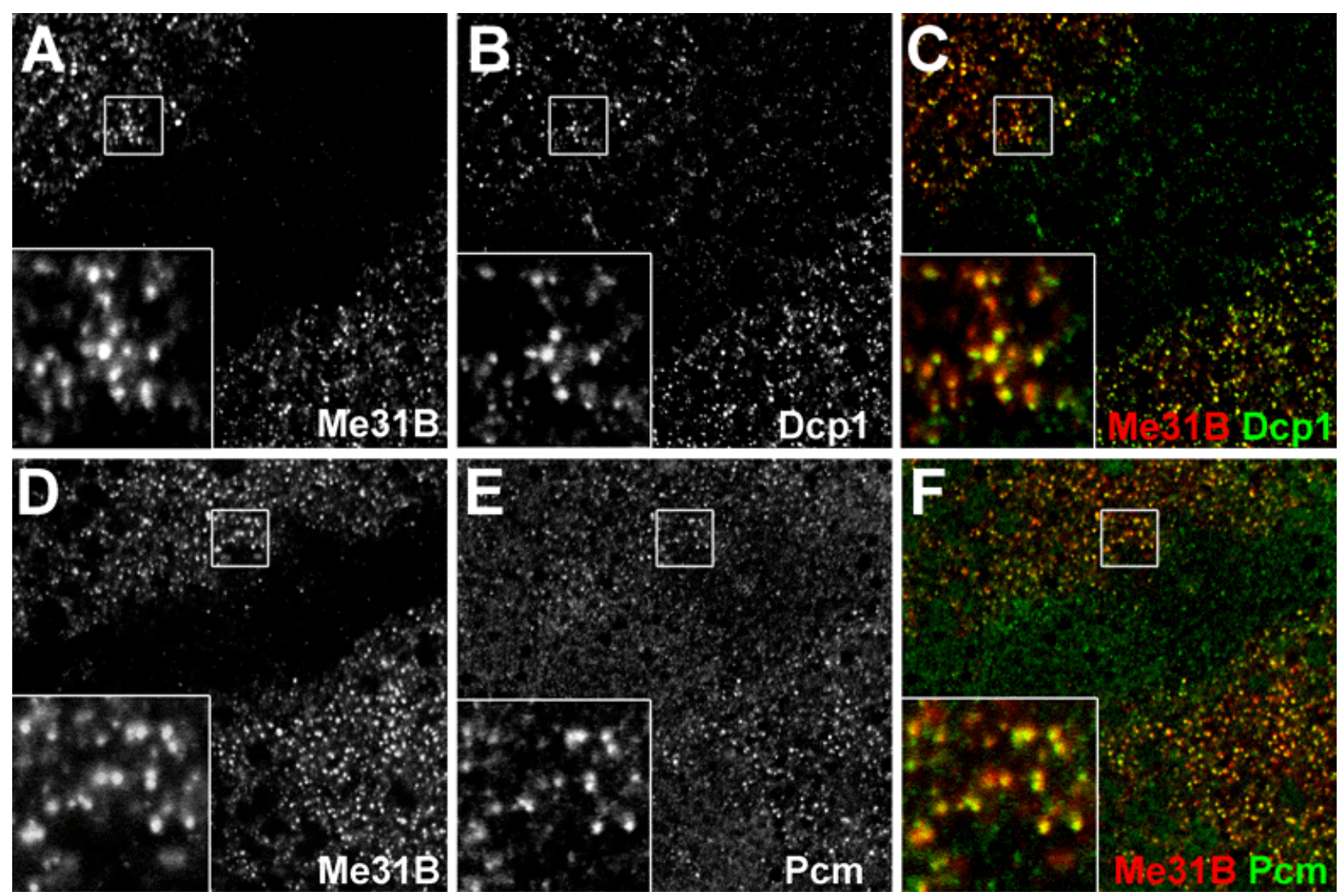

FIGURE 2. Depletion of Me31B reduces Dcp1 and Pacman (Pcm) expression. High-resolution images of wing imaginal discs, showing the colocalization of Me31B in cytoplasmic foci with the P-body components Dcp1(B and C) and Pcm (E and F), the Drosophila homologue of the exoribonuclease Xrn1. Depleting Me31B by RNAi[12] induces the loss of P-bodies in the wing imaginal disc; less bright Dcp1 and Pcm expressing foci can be observed in areas where Me31B is depleted (marked by the absence of Me31B in A). Expression of a Me31B hairpin construct[12] was driven with patched-Gal4 (Bloomington), reducing Me31B expression at the anterior/posterior boundary of the wing imaginal disc. Wing discs of 3rd instar larvae were dissected, fixed with $4 \%$ formaldehyde, and double stained with $\alpha$-Me31B[43] and $\alpha$-Dcp1[12] or $\alpha-\operatorname{Pcm}[12]$.

Me31B is also required to recruit specific translational regulators to P-bodies in Drosophila. In cultured neurons, Me31B colocalizes with many conserved P-body and NG components including FMRP (Table 1)[12]. Here, we show that FMRP colocalizes to P-bodies with Me31B in wing imaginal discs (Fig. 3A-C) and S2 cells (Fig. 3D-F). The loss of Me31B inhibits the recruitment of FMRP to P-bodies (Fig. 3A-C). These results are interesting because of recent findings showing that: (a) FMRP and Me31B interact genetically and biochemically in Drosophila[12]; (b) FMRP colocalizes with Me31B and Tral, the Drosophila ortholog of RAP55/Scd6p, in granules in cleavage-stage embryos, and is required for normal Tral expression[69]; and (c) in the Drosophila germline, FMRP interacts with Orb, a homolog of the cytoplasmic polyadenylation binding protein, CPEB[70]. CPEB mediates many diverse processes including germ-cell development, cell division and cellular senescence, and synaptic plasticity[71].

Both Me31B/RCK and FMRP are core P-body components and translational repressors with important neuronal functions[12,72]. How are these functions (e.g., in dendritic branching) accomplished? One possibility is that Me31B and FMRP regulate neuronal processes by regulating miRNA and siRNA pathways[12,56,62]. The existing data are consistent with Me31B/RCK function as a direct regulator of the miRNA pathway. Me31B/RCK not only associates with Ago1, a key component of the miRNA pathway, but its depletion in wing imaginal discs also results in increased expression of a GFP-reporter mRNA, repressed by the bantam miRNA in vivo[12]. Function for Me31B outside of the bantam pathway is confirmed by new data indicating that Me $31 \mathrm{~B}$ is similarly required for translation repression mediated by a different miRNA, miR-2 (Fig. 4). 

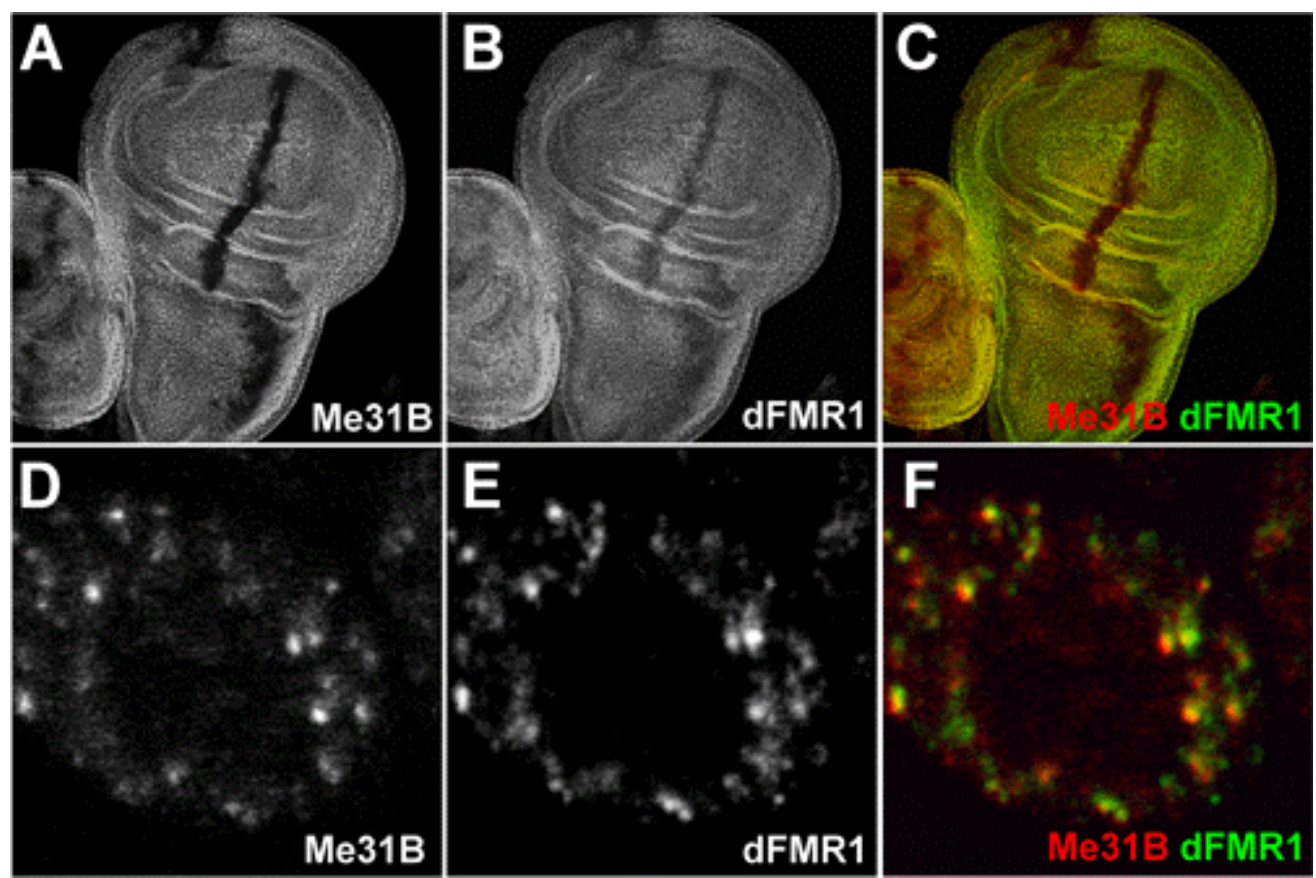

FIGURE 3. Depletion of Me31B reduces dFMR1 expression in wing imaginal discs, and Me31B and dFMR1 colocalize in P-bodies. (A-C) The loss of P-bodies in the wing imaginal disc by depletion of Me31B affects the recruitment of dFMR1 into foci. A Me31B hairpin construct[12] was expressed with patched-Gal4, reducing Me31B expression at the anterior/posterior boundary of the wing imaginal disc (marked by the absence of Me31B protein, A). For these experiments, wing discs of 3rd instar larvae were dissected, fixed with $4 \%$ formaldehyde and double stained with $\alpha$-Me31B[43] and $\alpha$-dFMR1 (5A11, Developmental Studies Hybridoma Bank). (D-F) In Drosophila Schneider, cells Me31B and dFMR1 colocalize in cytoplasmic foci, previously shown to be P-bodies (JH and MR, unpublished). For these experiments, Drosophila Schneider line 2 cells (S2) growing in M3 medium (Sigma) on glass cover slips were fixed with $4 \%$ Paraformaldehyde and counterstained with $\alpha$-Me31B[43] and $\alpha$-dFMR1 (5A11, Developmental Studies Hybridoma Bank).
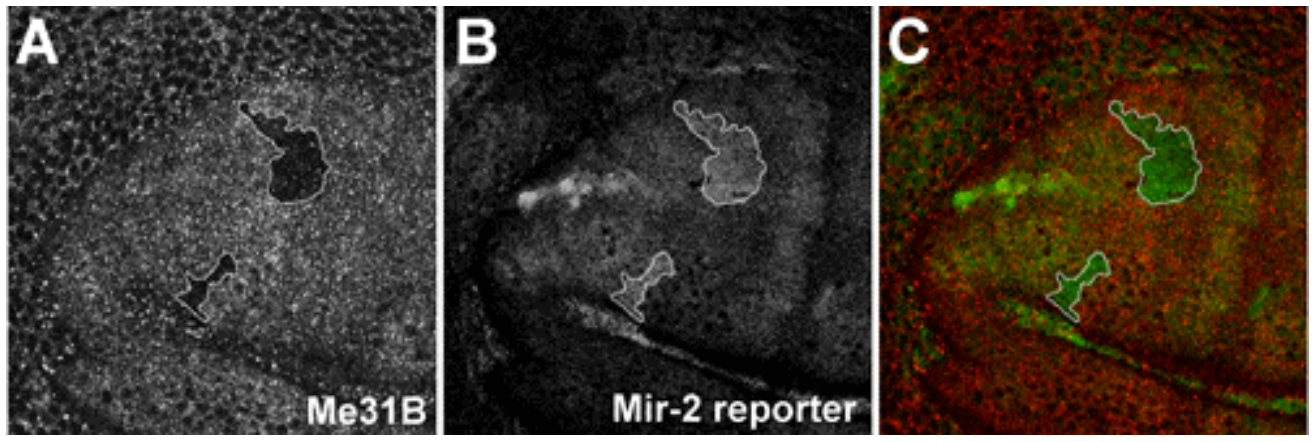

FIGURE 4. Me31B is required for the function of the endogenous microRNA mir-2. A mir-2 GFP-reporter[75] was used to measure the function of the endogenous miRNA mir-2. The up-regulation of GFP (B) in Me31B homozygous mutant clones (marked by the loss of Me31B expression, A) indicates that Me31B is required for the mir-2dependent repression of GFP. In these experiments, mitotic recombination clones were induced by the FRT/FLP system, $48 \pm 2 \mathrm{~h}$ after egg lay (AEL) by heat shock at $37^{\circ} \mathrm{C}$ for $90 \mathrm{~min}$; larval genotype used: hsFLP; Me31B D1, FRT 40/FRT 40, arm-lacZ; mir2-reporter/+. Wing discs were dissected $120 \pm 2 \mathrm{~h}$ AEL, fixed with $4 \%$ formaldehyde and double stained with $\alpha$-Me31B[43] and $\alpha$-GFP (Molecular Probes). 


\section{THE ROLE OF ME31B IN NEURONAL TRANSLATION}

Experimental studies of the conserved DEAD-box helicase Me31B/RCK link the molecular control of miRNA function with specific subcellular sites (P-bodies), and the cellular process of neuronal plasticity. To summarize, Me31B/RCK is required for: (a) P-body formation (Fig. 2); (b) miRNA function (Fig. 4); and (c) sensory neuron dendrite morphogenesis, a process regulated by translational repressor proteins[12]. Despite the excitement this model induces, it is important to note that several important issues need to be addressed before a definite role for the Me31B in the synaptic regulation of locally stored miRNA target mRNAs can be concluded.

First, it remains possible that Me31B functions in global translational control, and that its synaptic phenotypes do not reflect a role in the miRNA pathway or in local translation. Given that the unicellular yeast, which lacks a miRNA pathway, requires the Me31B ortholog Dhh1p for translational control, further experiments are essential. These should, at the very least, ask whether Me31B regulates the translation of synapse-localized mRNAs. New technologies need to be developed or implemented to establish a direct role in local translation.

The mechanism(s) by which Me31B/RCK/Dhh1p functions in translation is also unclear. The interaction of $\mathrm{Me} 31 \mathrm{~B} / \mathrm{RCK} / \mathrm{Dhh} 1 \mathrm{p}$ with numerous translational regulators like decapping enzymes, FMRP, RISC components, or CPEB[12,25,40,62,73] suggests a model where Me31B/RCK/Dhhlp recruits core P-body components and translational repressors, and mediates the aggregation of mRNPS into macroscopic mRNP particles, like P-bodies. Additionally, structural analysis of Dhh1p illustrates the potential RNA binding capability[74], substantiating the role of $\mathrm{Me} 31 \mathrm{~B} / \mathrm{RCK} / \mathrm{Dhh} 1 \mathrm{p}$ as a general translational repressor. However, to get further insight into the functional mechanisms of $\mathrm{Me} 31 \mathrm{~B} / \mathrm{RCK} / \mathrm{Dhh} 1 \mathrm{p}$ more detailed investigations are required.

In Drosophila, Me31B is required to recruit core components of P-bodies (Fig. 2) and NGs (Fig. 3) to macroscopic P-bodies in wing imaginal disc cells. The requirement of Me31B to recruit FMRP to Pbodies is of particular interest given that FMRP is present on NGs, interacts with RISC components, and acts as a regulator of synaptic plasticity[12,54,55,57,58]. How does Me31B's role in neuronal translational control derive from its interactions with FMRP, Tral, and other associated proteins? Me31Brepressed mRNAs can be derepressed and translated. To understand how repression is achieved and regulated, the identification of the interaction of Me31B with other proteins is important and must be interpreted in the context of dynamic and regulatable functions in vivo.

Another issue that remains unclear is the precise relationship between the accumulation of macroscopic P-bodies and miRNA function. Recent studies in Drosophila cell culture suggest that the regulation of miRNA function by P-body components does not require the formation of large Pbodies[19]. But what is the size of a functional P-body? The simplest model is that there is a pool of microscopic (not detectable by light microscopy) P-bodies that are sufficient for a basal level of P-body function. Macroscopic (large) P-bodies may have additional functions that are independent of mRNA decay and general- and miRNA-mediated translational repression pathways[8]. In a neuronal context, it will be important to understand how these observations relate to macroscopic NGs. Are large NGs solely involved in transport? Understanding NG formation and particle dynamics will likely provide significant insight into the mechanisms underlying synaptic mRNA translation.

Finally, and most importantly, we believe that major mechanistic insight into miRNA-mediated regulation of plasticity at the synapse will spring from the discovery that P-body components localize to Staufen- and FMRP-containing NGs[12]. Me31B, a shared component of P-bodies and NGs, is required for miRNA-mediated translational repression outside the nervous system, and ongoing experiments are designed to test the obvious hypothesis that Me31B mediates similar functions in neurons. Like Me31B, other core P-body components, including Dcp1/Dcp2 and GW182, appear to be intimately involved in translational regulation via the miRNA pathway. Thus, it is highly likely that more P-body components are involved. 


\section{CONCLUDING THOUGHTS}

Localization of P-bodies to neurites in Drosophila cell culture suggests that P-body formation and function may play a critical role in regulating, either directly or indirectly, local translation at the synapse - a mechanism widely held as essential for protein synthesis-dependent forms of LTM. To test and expand on this clearly articulated and increasingly well-supported hypothesis, future experiments need to address five broad questions. First, do P-body components regulate the translation of neuronal mRNAs? Second, do P-body components regulate the function of neuronal miRNAs? Third, are P-body components directly required (via a general- and/or miRNA-dependant mechanism) for regulation of local translation at the synapse? Fourth, is synaptic RNA turnover regulated by neuronal activity? Finally, are P-body components required for the formation of long-term memory?

\section{ACKNOWLEDGMENTS}

This work was supported by a postdoctoral NRSA from the National Institute of Health (MH074262) to $\mathrm{SAB}$, generous support to MR from the Science Foundation of Ireland, and the National Institute of Drug Abuse. We thank Akira Nakamura for his advice and generous help with analysis of Me31B. Special thanks are due to Roy Parker for sharing his remarkable insights into P-bodies and mRNA regulation.

\section{REFERENCES}

1. Sutton, M.A. and Schuman, E.M. (2006) Dendritic protein synthesis, synaptic plasticity, and memory. Cell 127, 4958.

2. Kiebler, M.A. and Bassell, G.J. (2006) Neuronal RNA granules: movers and makers. Neuron 51, 685-690.

3. Martin, K.C. and Zukin, R.S. (2006) RNA trafficking and local protein synthesis in dendrites: an overview. $J$. Neurosci. 26, 7131-7134.

4. Wu, C.W., Zeng, F., and Eberwine, J. (2007) mRNA transport to and translation in neuronal dendrites. Anal. Bioanal. Chem. 387, 59-62.

5. Schuman, E.M., Dynes, J.L., and Steward, O. (2006) Synaptic regulation of translation of dendritic mRNAs. J. Neurosci. 26, 7143-7146.

6. Ule, J. and Darnell, R.B. (2006) RNA binding proteins and the regulation of neuronal synaptic plasticity. Curr. Opin. Neurobiol. 16, 102-110.

7. $\quad$ Anderson, P. and Kedersha, N. (2006) RNA granules. J. Cell Biol. 172, 803-808.

8. Parker, R. and Sheth, U. (2007) P bodies and the control of mRNA translation and degradation. Mol. Cell 25, 635646.

9. Sossin, W.S. and DesGroseillers, L. (2006) Intracellular trafficking of RNA in neurons. Traffic 7, 1581-1589.

10. Kosik, K.S. (2006) The neuronal microRNA system. Nat. Rev. Neurosci. 7, 911-920.

11. Ashraf, S.I. and Kunes, S. (2006) A trace of silence: memory and microRNA at the synapse. Curr. Opin. Neurobiol. 16, 535-539.

12. Barbee, S.A., Estes, P.S., Cziko, A.M., Hillebrand, J., Luedeman, R.A., Coller, J.M., Johnson, N., Howlett, I.C., Geng, C., Ueda, R., Brand, A.H., Newbury, S.F., Wilhelm, J.E., Levine, R.B., Nakamura, A., Parker, R., and Ramaswami, M. (2006) Staufen- and FMRP-containing neuronal RNPs are structurally and functionally related to somatic P bodies. Neuron 52, 997-1009.

13. Brengues, M., Teixeira, D., and Parker, R. (2005) Movement of eukaryotic mRNAs between polysomes and cytoplasmic processing bodies. Science 310, 486-489.

14. Eulalio, A., Behm-Ansmant, I., and Izaurralde, E. (2007) P bodies: at the crossroads of post-transcriptional pathways. Nat. Rev. 8, 9-22.

15. Jakymiw, A., Pauley, K.M., Li, S., Ikeda, K., Lian, S., Eystathioy, T., Satoh, M., Fritzler, M.J., and Chan, E.K. (2007) The role of GW/P-bodies in RNA processing and silencing. J. Cell Sci. 120, 1317-1323.

16. Lian, S., Jakymiw, A., Eystathioy, T., Hamel, J.C., Fritzler, M.J., and Chan, E.K. (2006) GW bodies, microRNAs and the cell cycle. Cell Cycle 5, 242-245.

17. Ashraf, S.I., McLoon, A.L., Sclarsic, S.M., and Kunes, S. (2006) Synaptic protein synthesis associated with memory is regulated by the RISC pathway in Drosophila. Cell 124, 191-205.

18. Schratt, G.M., Tuebing, F., Nigh, E.A., Kane, C.G., Sabatini, M.E., Kiebler, M., and Greenberg, M.E. (2006) A brainspecific microRNA regulates dendritic spine development. Nature 439, 283-289. 
19. Eulalio, A., Behm-Ansmant, I., Schweizer, D., and Izaurralde, E. (2007) P-body formation is a consequence, not the cause, of RNA-mediated gene silencing. Mol. Cell. Biol. 27, 3970-3981.

20. Kiebler, M.A., Hemraj, I., Verkade, P., Kohrmann, M., Fortes, P., Marion, R.M., Ortin, J., and Dotti, C.G. (1999) The mammalian staufen protein localizes to the somatodendritic domain of cultured hippocampal neurons: implications for its involvement in mRNA transport. J. Neurosci. 19, 288-297.

21. Thomas, M.G., Martinez Tosar, L.J., Loschi, M., Pasquini, J.M., Correale, J., Kindler, S., and Boccaccio, G.L. (2005) Staufen recruitment into stress granules does not affect early mRNA transport in oligodendrocytes. Mol. Biol. Cell 16, 405-420.

22. De Diego Otero, Y., Severijnen, L.A., van Cappellen, G., Schrier, M., Oostra, B., and Willemsen, R. (2002) Transport of fragile X mental retardation protein via granules in neurites of PC12 cells. Mol. Cell. Biol. 22, 8332-8341. Mazroui, R., Huot, M.E., Tremblay, S., Filion, C., Labelle, Y., and Khandjian, E.W. (2002) Trapping of messenger RNA by Fragile X Mental Retardation protein into cytoplasmic granules induces translation repression. Hum. Mol. Genet. 11, 3007-3017.

24. Kanai, Y., Dohmae, N., and Hirokawa, N. (2004) Kinesin transports RNA: isolation and characterization of an RNAtransporting granule. Neuron 43, 513-525.

25. Sheth, U. and Parker, R. (2003) Decapping and decay of messenger RNA occur in cytoplasmic processing bodies. Science 300, 805-808.

26. Wilczynska, A., Aigueperse, C., Kress, M., Dautry, F., and Weil, D. (2005) The translational regulator CPEB1 provides a link between dcp1 bodies and stress granules. J. Cell Sci. 118, 981-992.

27. Cougot, N., Babajko, S., and Seraphin, B. (2004) Cytoplasmic foci are sites of mRNA decay in human cells. J. Cell Biol. 165, 31-40.

28. Kedersha, N. and Anderson, P. (2002) Stress granules: sites of mRNA triage that regulate mRNA stability and translatability. Biochem. Soc. Trans. 30, 963-969.

29. Kedersha, N., Chen, S., Gilks, N., Li, W., Miller, I.J., Stahl, J., and Anderson, P. (2002) Evidence that ternary complex (eIF2-GTP-tRNA(i)(Met))-deficient preinitiation complexes are core constituents of mammalian stress granules. Mol. Biol. Cell 13, 195-210.

30. Krichevsky, A.M. and Kosik, K.S. (2001) Neuronal RNA granules: a link between RNA localization and stimulationdependent translation. Neuron 32, 683-696.

31. Andrei, M.A., Ingelfinger, D., Heintzmann, R., Achsel, T., Rivera-Pomar, R., and Luhrmann, R. (2005) A role for eIF4E and eIF4E-transporter in targeting mRNPs to mammalian processing bodies. RNA 11, 717-727.

Antar, L.N., Dictenberg, J.B., Plociniak, M., Afroz, R., and Bassell, G.J. (2005) Localization of FMRP-associated mRNA granules and requirement of microtubules for activity-dependent trafficking in hippocampal neurons. Genes Brain Behav. 4, 350-359.

33. Kedersha, N., Cho, M.R., Li, W., Yacono, P.W., Chen, S., Gilks, N., Golan, D.E., and Anderson, P. (2000) Dynamic shuttling of TIA-1 accompanies the recruitment of mRNA to mammalian stress granules. J. Cell Biol. 151, 12571268 .

34. Kedersha, N., Stoecklin, G., Ayodele, M., Yacono, P., Lykke-Andersen, J., Fritzler, M.J., Scheuner, D., Kaufman, R.J., Golan, D.E., and Anderson, P. (2005) Stress granules and processing bodies are dynamically linked sites of mRNP remodeling. J. Cell Biol. 169, 871-884.

35. Behm-Ansmant, I., Rehwinkel, J., Doerks, T., Stark, A., Bork, P., and Izaurralde, E. (2006) mRNA degradation by miRNAs and GW182 requires both CCR4:NOT deadenylase and DCP1:DCP2 decapping complexes. Genes Dev. 20, 1885-1898.

36. Ding, L., Spencer, A., Morita, K., and Han, M. (2005) The developmental timing regulator AIN-1 interacts with miRISCs and may target the argonaute protein ALG-1 to cytoplasmic P bodies in C. elegans. Mol. Cell 19, 437-447.

37. Liu, J., Valencia-Sanchez, M.A., Hannon, G.J., and Parker, R. (2005) MicroRNA-dependent localization of targeted mRNAs to mammalian P-bodies. Nat. Cell Biol. 7, 719-723.

38. Sen, G.L. and Blau, H.M. (2005) Argonaute 2/RISC resides in sites of mammalian mRNA decay known as cytoplasmic bodies. Nat. Cell Biol. 7, 633-636.

39. Tanaka, K.J., Ogawa, K., Takagi, M., Imamoto, N., Matsumoto, K., and Tsujimoto, M. (2006) RAP55, a cytoplasmic mRNP component, represses translation in Xenopus oocytes. J. Biol. Chem. 281, 40096-40106.

40. Coller, J. and Parker, R. (2005) General translational repression by activators of mRNA decapping. Cell 122, 875886.

41. Ladomery, M., Wade, E., and Sommerville, J. (1997) Xp54, the Xenopus homologue of human RNA helicase p54, is an integral component of stored mRNP particles in oocytes. Nucleic Acids Res. 25, 965-973.

42. Minshall, N., Thom, G., and Standart, N. (2001) A conserved role of a DEAD box helicase in mRNA masking. RNA 7, 1728-1742.

43. Nakamura, A., Amikura, R., Hanyu, K., and Kobayashi, S. (2001) Me31B silences translation of oocyte-localizing RNAs through the formation of cytoplasmic RNP complex during Drosophila oogenesis. Development 128, 32333242.

44. Navarro, R.E., Shim, E.Y., Kohara, Y., Singson, A., and Blackwell, T.K. (2001) cgh-1, a conserved predicted RNA helicase required for gametogenesis and protection from physiological germline apoptosis in C. elegans. Development 128, 3221-3232. 
45. Lewis, B.P., Burge, C.B., and Bartel, D.P. (2005) Conserved seed pairing, often flanked by adenosines, indicates that thousands of human genes are microRNA targets. Cell 120, 15-20.

46. Miska, E.A., Alvarez-Saavedra, E., Townsend, M., Yoshii, A., Sestan, N., Rakic, P., Constantine-Paton, M., and Horvitz, H.R. (2004) Microarray analysis of microRNA expression in the developing mammalian brain. Genome Biol. 5, R68.

47. Sempere, L.F., Freemantle, S., Pitha-Rowe, I., Moss, E., Dmitrovsky, E., and Ambros, V. (2004) Expression profiling of mammalian microRNAs uncovers a subset of brain-expressed microRNAs with possible roles in murine and human neuronal differentiation. Genome Biol. 5, R13.

48. Kim, J., Krichevsky, A., Grad, Y., Hayes, G.D., Kosik, K.S., Church, G.M., and Ruvkun, G. (2004) Identification of many microRNAs that copurify with polyribosomes in mammalian neurons. Proc. Natl. Acad. Sci. U. S. A. 101, 360365.

49. Lagos-Quintana, M., Rauhut, R., Yalcin, A., Meyer, J., Lendeckel, W., and Tuschl, T. (2002) Identification of tissuespecific microRNAs from mouse. Curr. Biol. 12, 735-739.

50. Matsuzaki, M., Honkura, N., Ellis-Davies, G.C., and Kasai, H. (2004) Structural basis of long-term potentiation in single dendritic spines. Nature 429, 761-766.

51. Nagerl, U.V., Eberhorn, N., Cambridge, S.B., and Bonhoeffer, T. (2004) Bidirectional activity-dependent morphological plasticity in hippocampal neurons. Neuron 44, 759-767.

52. Zito, K., Knott, G., Shepherd, G.M., Shenolikar, S., and Svoboda, K. (2004) Induction of spine growth and synapse formation by regulation of the spine actin cytoskeleton. Neuron 44, 321-334.

53. Irwin, S.A., Galvez, R., and Greenough, W.T. (2000) Dendritic spine structural anomalies in fragile-X mental retardation syndrome. Cereb. Cortex 10, 1038-1044.

54. Michel, C.I., Kraft, R., and Restifo, L.L. (2004) Defective neuronal development in the mushroom bodies of Drosophila fragile X mental retardation 1 mutants. J. Neurosci. 24, 5798-5809.

55. Pan, L., Zhang, Y.Q., Woodruff, E., and Broadie, K. (2004) The Drosophila fragile X gene negatively regulates neuronal elaboration and synaptic differentiation. Curr. Biol. 14, 1863-1870.

56. Caudy, A.A., Myers, M., Hannon, G.J., and Hammond, S.M. (2002) Fragile X-related protein and VIG associate with the RNA interference machinery. Genes Dev. 16, 2491-2496.

57. Jin, P., Zarnescu, D.C., Ceman, S., Nakamoto, M., Mowrey, J., Jongens, T.A., Nelson, D.L., Moses, K., and Warren, S.T. (2004) Biochemical and genetic interaction between the fragile $\mathrm{X}$ mental retardation protein and the microRNA pathway. Nat. Neurosci. 7, 113-117.

58. Siomi, H., Ishizuka, A., and Siomi, M.C. (2004) RNA interference: a new mechanism by which FMRP acts in the normal brain? What can Drosophila teach us? Ment. Retard. Dev. Disabil. Res. Rev. 10, 68-74.

59. Klein, M.E., Impey, S., and Goodman, R.H. (2005) Role reversal: the regulation of neuronal gene expression by microRNAs. Curr. Opin. Neurobiol. 15, 507-513.

60. Kosik, K.S. and Krichevsky, A.M. (2005) The elegance of the microRNAs: a neuronal perspective. Neuron 47, 779782.

61. Valencia-Sanchez, M.A., Liu, J., Hannon, G.J., and Parker, R. (2006) Control of translation and mRNA degradation by miRNAs and siRNAs. Genes Dev. 20, 515-524.

62. Chu, C.Y. and Rana, T.M. (2006) Translation repression in human cells by microRNA-induced gene silencing requires RCK/p54. PLoS Biol. 4, e210.

63. Jakymiw, A., Lian, S., Eystathioy, T., Li, S., Satoh, M., Hamel, J.C., Fritzler, M.J., and Chan, E.K. (2005) Disruption of GW bodies impairs mammalian RNA interference. Nat. Cell Biol. 7, 1267-1274.

64. Meister, G., Landthaler, M., Peters, L., Chen, P.Y., Urlaub, H., Luhrmann, R., and Tuschl, T. (2005) Identification of novel argonaute-associated proteins. Curr. Biol. 15, 2149-2155.

65. Rehwinkel, J., Behm-Ansmant, I., Gatfield, D., and Izaurralde, E. (2005) A crucial role for GW182 and the DCP1:DCP2 decapping complex in miRNA-mediated gene silencing. RNA 11, 1640-1647.

66. Jing, Q., Huang, S., Guth, S., Zarubin, T., Motoyama, A., Chen, J., Di Padova, F., Lin, S.C., Gram, H., and Han, J. (2005) Involvement of microRNA in AU-rich element-mediated mRNA instability. Cell 120, 623-634.

67. Liu, J., Rivas, F.V., Wohlschlegel, J., Yates, J.R., 3rd, Parker, R., and Hannon, G.J. (2005) A role for the P-body component GW182 in microRNA function. Nat. Cell Biol. 7, 1261-1266.

68. Pauley, K.M., Eystathioy, T., Jakymiw, A., Hamel, J.C., Fritzler, M.J., and Chan, E.K. (2006) Formation of GW bodies is a consequence of microRNA genesis. EMBO Rep. 7, 904-910.

69. Monzo, K., Papoulas, O., Cantin, G.T., Wang, Y., Yates, J.R., 3rd, and Sisson, J.C. (2006) Fragile X mental retardation protein controls trailer hitch expression and cleavage furrow formation in Drosophila embryos. Proc. Natl. Acad. Sci. U. S. A. 103, 18160-18165.

70. Costa, A., Wang, Y., Dockendorff, T.C., Erdjument-Bromage, H., Tempst, P., Schedl, P., and Jongens, T.A. (2005) The Drosophila fragile $\mathrm{X}$ protein functions as a negative regulator in the orb autoregulatory pathway. Dev. Cell 8, 331-342.

71. Richter, J.D. (2007) CPEB: a life in translation. Trends Biochem. Sci. 32(6), 279-285.

72. Nimchinsky, E.A., Oberlander, A.M., and Svoboda, K. (2001) Abnormal development of dendritic spines in FMR1 knock-out mice. J. Neurosci. 21, 5139-5146.

73. Minshall, N. and Standart, N. (2004) The active form of Xp54 RNA helicase in translational repression is an RNA- 
mediated oligomer. Nucleic Acids Res. 32, 1325-1334.

74. Cheng, Z., Coller, J., Parker, R., and Song, H. (2005) Crystal structure and functional analysis of DEAD-box protein Dhh1p. RNA 11, 1258-1270.

75. Brennecke, J., Stark, A., Russell, R.B., and Cohen, S.M. (2005) Principles of microRNA-target recognition. PLoS Biol. 3, e85.

76. Pillai, R.S., Bhattacharyya, S.N., Artus, C.G., Zoller, T., Cougot, N., Basyuk, E., Bertrand, E., and Filipowicz, W. (2005) Inhibition of translational initiation by Let-7 MicroRNA in human cells. Science 309, 1573-1576.

77. Macchi, P., Kroening, S., Palacios, I.M., Baldassa, S., Grunewald, B., Ambrosino, C., Goetze, B., Lupas, A., St Johnston, D., and Kiebler, M. (2003) Barentsz, a new component of the Staufen-containing ribonucleoprotein particles in mammalian cells, interacts with Staufen in an RNA-dependent manner. J. Neurosci. 23, 5778-5788.

78. Teixeira, D., Sheth, U., Valencia-Sanchez, M.A., Brengues, M., and Parker, R. (2005) Processing bodies require RNA for assembly and contain nontranslating mRNAs. RNA 11, 371-382.

79. Ye, B., Petritsch, C., Clark, I.E., Gavis, E.R., Jan, L.Y., and Jan, Y.N. (2004) Nanos and Pumilio are essential for dendrite morphogenesis in Drosophila peripheral neurons. Curr. Biol. 14, 314-321.

80. Sigrist, S.J., Thiel, P.R., Reiff, D.F., Lachance, P.E., Lasko, P., and Schuster, C.M. (2000) Postsynaptic translation affects the efficacy and morphology of neuromuscular junctions. Nature 405, 1062-1065.

81. Kim, Y.K., Furic, L., Desgroseillers, L., and Maquat, L.E. (2005) Mammalian Staufen1 recruits Upf1 to specific mRNA 3'UTRs so as to elicit mRNA decay. Cell 120, 195-208.

82. Yang, W.H., Yu, J.H., Gulick, T., Bloch, K.D., and Bloch, D.B. (2006) RNA-associated protein 55 (RAP55) localizes to mRNA processing bodies and stress granules. RNA 12, 547-554.

\section{This article should be cited as follows:}

Hillebrand, J., Barbee, S.A., and Ramaswami, M. (2007) P-body components, microRNA regulation, and synaptic plasticity. TheScientificWorldJOURNAL 7(S2), 178-190. DOI 10.1100/tsw.2007.206. 

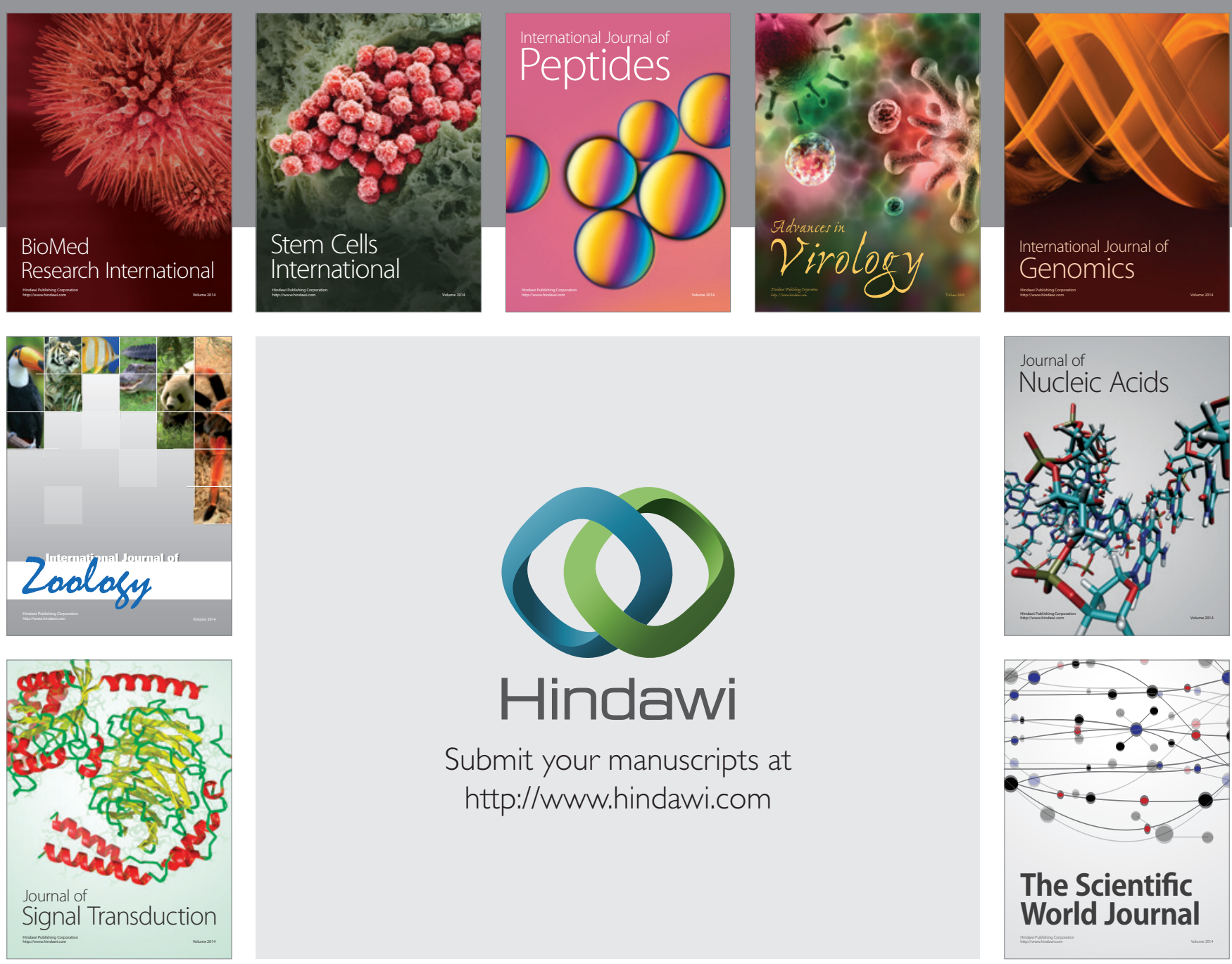

Submit your manuscripts at

http://www.hindawi.com
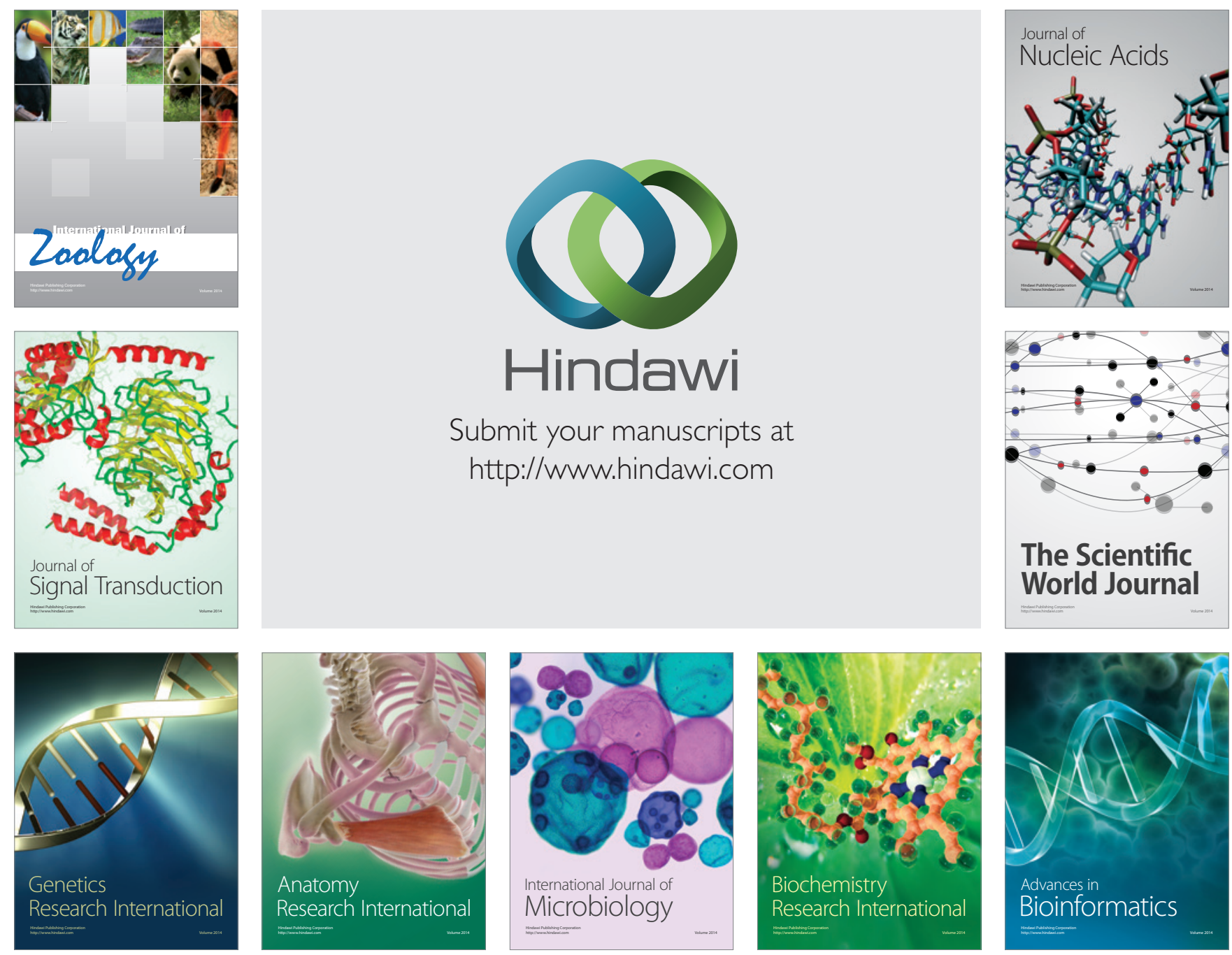

The Scientific World Journal
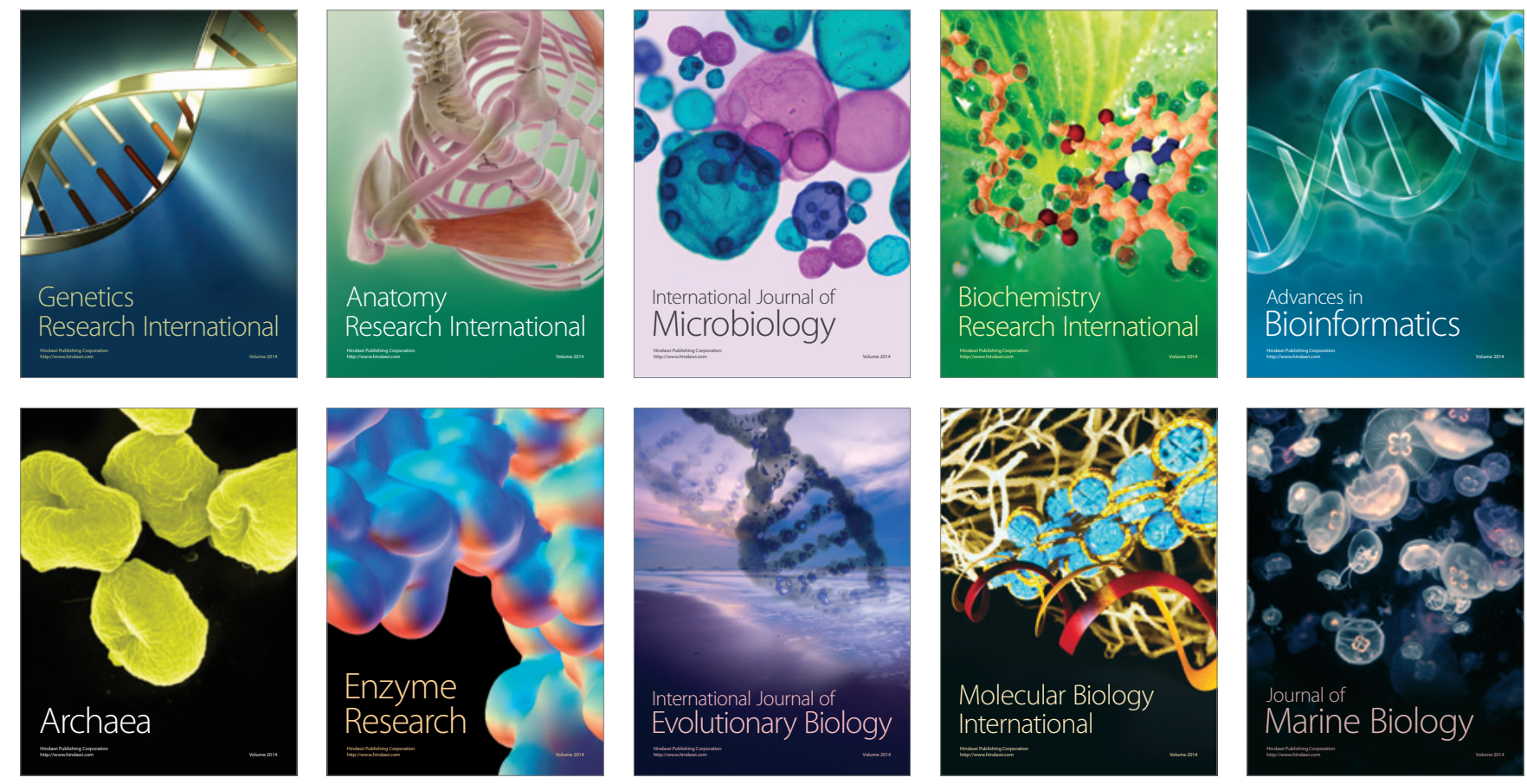